\title{
EL CONCEPTO DE LIBERTAD EN LA TEORÍA POLÍTICA DE NORBERTO BOBBIO
}

Carlos Bernal Pulido*

\section{INTRODUCCIÓN}

Torberto Bobbio fue uno de los filósofos del derecho y de la 1 política más destacados del siglo $\mathrm{xx}$, y uno de los principales protagonistas del debate político italiano en la segunda posguerra. Su obra filosófico-jurídica -de la que sus teorías generales de la norma y del ordenamiento jurídico son quizás su expresión más significativa (Bobbio, 1988) - tiene el mérito de haber anticipado en el ámbito continental la aplicación de la filosofía analítica al estudio de la naturaleza y la función del derecho. Bobbio fue pionero en esta senda, trasegada luego no sólo en Italia, por discípulos de la talla de Luigi Ferrajoli, sino en España y en América Latina.

Pero tal vez sean sus contribuciones a la filosofía política las que lo llevaron a adquirir renombre mundial. Éstas incluyen más de una decena de libros y un centenar de artículos, de los cuales los más emblemáticos fueron traducidos al castellano y publicados hace poco bajo el cuidado de Michelangelo Bovero, en la abrumadora compilación Teoría general de la política. Esta teoría no descuida ni uno sólo de los tópicos esenciales de la filosofía política y los trata con el rigor y la crítica inmisericorde característicos de Bobbio. La obra sistematiza un análisis pormenorizado de las ideas de los clásicos hasta las de los autores más recientes -en cinco idiomas- sobre la democracia, la igualdad, la libertad, los valores, la paz y la guerra, y los derechos humanos. Su importancia sobrepasa las fronteras italianas, europeas

\footnotetext{
* Profesor de Introducción al Derecho y Derecho Constitucional de la Universidad Externado de Colombia, carlos.bernal@uexternado.edu.co Fecha de recepción: 28 de octubre de 2005, fecha de aceptación: 2 de marzo de 2006.
} 
y las del mundo latino, como evidencian los incontables artículos, libros, compilaciones y tesis doctorales que se han escrito en el orbe entero sobre el pensamiento de Bobbio. Es significativo que en el último congreso mundial de la Asociación Internacional de Filosofía del Derecho, que tuvo lugar en Granada a finales de mayo de 2005, se tributara un merecido homenaje a la obra de este autor.

Por esas razones, por la influencia de su pensamiento entre nosotros y por el recuerdo indeleble que dejó su visita al Externado a finales de los años ochenta es justo recordar a este pensador con el homenaje más honroso que se puede ofrecer a un hombre de letras y de ciencia: la discusión de sus ideas.

\section{EL ANÁLISIS DEL CONCEPTO DE LIBERTAD}

Uno de los aspectos más relevantes de la teoría política de Bobbio fue el estudio de los valores. La perspectiva analítica que siempre privilegió lo llevó a tratar de reconstruir el significado o los significados descriptivos de los valores. Su pretensión era abordar ese estudio desde una óptica científica, ajena a la manipulación retórica, que arrojara la mayor claridad posible sobre cada concepto. Si se quiere, lo que el filósofo de Turín perseguía era tratar los valores desde un punto de vista avalorativo; así, su contribución se puede poner en consonancia con obras como Dimensiones de la libertad de Oppenheim. Como punto de partida reconoció la posibilidad de describir los valores, es decir, de reconstruir el significado o los significados descriptivos de las nociones de valor, de acuerdo con las reglas de uso lingüístico que los rigen. Tras la aplicación de este método analítico es posible asumir o refutar el valor con la conciencia de que la asunción o la refutación no se derivan directamente del significado descriptivo de cada noción.

En cuanto valor, la libertad tiene significados descriptivos que se deben reconstruir de conformidad con las reglas de uso lingüístico que operan en la comunidad en general y en la comunidad científica en particular. Uno de los objetos centrales de la teoría política de Bobbio fue el de esclarecer esos conceptos descriptivos de libertad. En este sentido, su contribución se sitúa junto a estudios clásicos como el de Constant sobre la libertad de los antiguos y la libertad de los modernos o el genial ensayo de Berlin Two Concepts of Liberty, ya bien difundido en el mundo hispano.

Este escrito pretende ser una metarreconstrucción crítica del concepto de libertad de Norberto Bobbio. Metarreconstrucción, por 
cuanto se propone reconstruir su reconstrucción de los conceptos descriptivos de libertad. Crítica, porque se pregunta además si la reconstrucción de Bobbio es adecuada o no. La filosofía analítica-que él bien aplicó- nos hizo ver que no existen esencias conceptuales, es decir, que los conceptos no guardan correspondencia con esencias de ningún tipo, sino que son el producto de los usos lingüísticos de la comunidad. Desde este punto de vista, cuando se ha de analizar un concepto como el de libertad, la tarea del analista no es "descubrir" la "verdadera esencia" de un objeto del mundo que corresponda en realidad a la libertad, sino reconstruir los significados de este término en los discursos filosóficos, jurídicos, políticos y de la comunidad en general. Con todo, esta manera de proceder no hace de la filosofía política ni de la filosofía general una mera ciencia descriptiva de convenciones lingüísticas. No podemos olvidar la vieja lección de Kant en su Crítica de la razón pura, cuando afirmó que siempre es legítimo preguntarse si los conceptos resultan adecuados a sus objetos.

En ese sentido, este ensayo no sólo busca reconstruir la reconstrucción del concepto o de los conceptos de libertad que hizo Bobbio, sino que también se pregunta si esta reconstrucción es adecuada a su objeto. Para ello se divide en dos partes. En la primera parte se reconstruye el concepto de libertad en la teoría política de Norberto Bobbio. En la segunda se analiza la adecuación de este concepto a su objeto.

\section{LA RECONSTRUCCIÓN DEL CONCEPTO DE LIBERTAD SEGÚN BOBBIO}

\section{LOS CONCEPTOS DE LIBERTAD DE BOBBIO}

Una preocupación permanente de Bobbio fue la de esclarecer los significados descriptivos del concepto de libertad. Para él, esta tarea analítica era un presupuesto conceptual previo a cualquier otra discusión sobre la estructuración política de los valores en la sociedad. Así lo muestran vehementemente sus propias palabras: “¿Qué sentido tendría decir 'prefiero la libertad' si no se establece antes en cuál de los sentidos descriptivos de libertad empleo esta palabra en este contexto?”. A las que añade:

Una reflexión sobre la libertad sólo tiene sentido si se apoya en un significado descriptivo bien determinado y bien delimitado del término. El significado valorativo viene después, es un significado añadido. El que "libertad" tenga un significado valorativo quiere decir tan sólo esto: que cuando empleo este 
término indico, además, que una cierta situación está determinada en un cierto sentido, que es también una situación "buena", que recomiendo. Pero lo que cuenta en la reflexión sobre la libertad no es tanto el saber que aquella situación de la que se habla resulta deseable y recomendable, sino qué es lo que el interlocutor desea y recomienda (Passerin D'Entreves, 1974, 296).

Bobbio dedicó encomiables empeños a lo largo de varias décadas ${ }^{1}$ a responder esta pregunta: qué es lo que el interlocutor desea y recomienda cuando se refiere a la libertad. Quizá puso la primera piedra en su artículo "De la libertad de los modernos comparada con la de los posteriores", famoso por su título satírico. En este bienquisto texto inició la tarea de clarificación y distinción de los significados descriptivos del término "libertad". Desde entonces, sostuvo que tenía sobre todo dos significados descriptivos: la libertad de tinte liberal - llamada también libertad negativa o no impedimento-, a la que entendía como la facultad de realizar o no realizar ciertas acciones, sin impedimento externo; y la libertad democrática, a la que denominó a veces libertad positiva o no-constricción y definió como el poder de darse leyes a sí mismo.

Es imposible pasar de largo por este texto de Bobbio sin destacar que desde aquel entonces planteó con toda claridad los principales rasgos de la dicotomía entre libertad negativa y libertad positiva, que en el mundo anglosajón luego diera gran renombre a Isaiah Berlin, cuyo texto es cuatro años posterior al de Bobbio. Como veremos más adelante existen diferencias importantes en el enfoque de estos dos autores. Con todo, sus coincidencias son notables.

Once años después de publicar "De la libertad de los modernos comparada con la de los posteriores", Bobbio se aproximó de nuevo al concepto de la libertad en "Kant y las dos libertades". En este segundo texto Bobbio sustituyó la denominación del concepto de libertad democrática por el de autonomía. Es cierto que en el primero había aludido a la autonomía, cuando explicó el concepto de libertad que defendía la teoría democrática. Pero en el segundo la autonomía está situada en el centro de este nuevo significado descriptivo de libertad.

Luego, en la voz "Libertad" que redactó para la Enciclopedia del Novecento, el concepto de no constricción quedó absorbido en la definición de la primera libertad, la libertad liberal, y se convirtió en un aspecto complementario del no impedimento. Y la autonomía se mantuvo como significado esencial de la segunda libertad, la libertad democrática. Esta variación se produjo porque Bobbio consideraba

${ }^{1}$ En esta periodización sigo a Bovero (2003, 43).

Revista de Economía Institucional, vol. 8, n.o i4, Primer semestre/2006 
en esa época que la no constricción y el no impedimento se refieren a la libertad de acción, y la autonomía a la libertad de la voluntad. Junto a esa tesis, reconocía que la dicotomía entre las esferas del actuar y el querer era la más pertinente para distinguir los significados descriptivos de la libertad.

En posteriores contribuciones ${ }^{2}$, Bobbio añadió un tercer significado, el de la libertad como la capacidad positiva material o poder positivo de hacer lo que la libertad negativa permite hacer. Reconoció que este tercer significado es una herencia del socialismo y que sirve de fundamento de los derechos sociales. También lo denomina libertad positiva y así provoca una confusión entre esta categoría y la libertad positiva entendida como autonomía, concepto muy citado a lo largo y ancho de su obra.

\section{TRES CONCEPTOS DE LIBERTAD}

E1 recuento anterior indica que para Bobbio son relevantes tres conceptos de libertad, los que reconstruiremos a continuación. De acuerdo con los usos que les dio con mayor frecuencia, permítaseme llamarlos libertad liberal, autonomía y libertad positiva. Para Bobbio, todos estos sentidos son legítimos; cada uno tiene validez en su propio ámbito. Por ello, carece de sentido preguntar cuál de ellos refleja la libertad "verdadera" o una libertad "mejor". Esa pregunta implica la absurda aceptación de que "por algún decreto divino, histórico o racional", existiría "un solo modo legítimo de entender el término libertad y que todos los demás están equivocados" (Bobbio, 1955).

En todo caso, Bobbio aseveró con vehemencia que todos estos sentidos de la libertad representan estados deseables y que, para su clarificación analítica, era pertinente formular dos preguntas: “¿libertad de quién?” y “¿libertad de qué?” (Bobbio, 1976). Emprendamos una reconstrucción de estos tres conceptos de libertad.

\section{La libertad liberal}

Libertad liberal es la locución que Bobbio escoge para referirse al concepto de libertad que utiliza la teoría liberal: "la facultad de realizar o no ciertas acciones sin ser impedido por los demás, por la sociedad como un todo orgánico o, más sencillamente, por el poder estatal" (Bobbio, 1965). Gracias a esta facultad, el individuo puede

\footnotetext{
${ }^{2}$ Las más relevantes son Bobbio (1963 y 1996).
} 
gozar de una esfera de acción, más o menos amplia, no controlada por los órganos del poder estatal. En ella se puede comportar como "el agua que corre sin cauce" (Bobbio, 1955). Este sentido de libertad corresponde al concepto de acción. Una acción libre es una acción lícita, que puedo hacer o no porque no está impedida.

Bobbio subraya que la esfera de la libertad liberal está compuesta por el conjunto de acciones no impedidas. En términos de teoría general del derecho, la esfera de lo permitido, es decir, de lo no obligatorio. Libertad es, en esta acepción, el "espacio no regulado por normas imperativas -positivas o negativas-" (Bobbio, 1965). Aquí la libertad tiene la misma extensión que la licitud (Bobbio, 1955), la misma extensión de la esfera de lo que está permitido por no estar ni ordenado ni prohibido. Se trata de la libertad negativa, la esfera de los comportamientos no regulados, y por tanto, lícitos o indiferentes, descrita por Montesquieu cuando señaló que la libertad consiste en hacer todo aquello que permiten las leyes, o por Hobbes cuando apuntó que la libertad es la situación en la que un sujeto actúa según su naturaleza, sin que se lo impidan fuerzas externas, en la esfera del ius o de los comportamientos lícitos (Bobbio, 1963).

Por ello, esta acepción de la libertad se contrapone al impedimento. Lo que busca con ella la doctrina liberal es "una disminución de la esfera de las órdenes y una extensión de la esfera de los permisos”. En consecuencia, la libertad liberal y su esfera de licitud trazan límites al ejercicio del poder del Estado. La máxima es: "el Estado debe gobernar lo menos posible, dado que la verdadera libertad consiste en no verse obstaculizado por un exceso de leyes" (Bobbio, 1955). Como correlato, todo ser humano debe tener una esfera de actividad personal protegida contra la injerencia de poderes externos, en particular del poder estatal (Bobbio, 1963).

\section{Autonomía}

El concepto de libertad también ha recibido un significado descriptivo, inconfundible con el anterior e insustituible, proveniente de la teoría democrática. Desde esta óptica, libertad significa autonomía, es decir, el "poder de no obedecer otras normas que las que me he impuesto a mí mismo" (Bobbio, 1965). Si se quiere, de manera antagónica a la libertad liberal, la autonomía indica que ser libre no significa no tener leyes, sino darse leyes a sí mismo. El demócrata no intenta eliminar todas las barreras posibles a la acción del sujeto, sino "aumentar el número de acciones regidas por procesos de autorreglamentación” (ibíd.). 
En términos de teoría general del derecho, este concepto de libertad coincide con la esfera de lo "obligatorio", si bien no de todo lo obligatorio, sólo de "aquello que es obligatorio en virtud de una autoobligación”. Libertad sería entonces el espacio regulado por normas imperativas, siempre que sean autónomas y no heterónomas.

Así entendida, la libertad se contrapone a la constricción y corresponde no a la acción, como la libertad liberal, sino a la voluntad. Como señala Bobbio, "una voluntad libre es una voluntad que se autodetermina” (1955). En esta acepción de libertad, la máxima es: "los miembros de un Estado se deben gobernar por sí mismos, ya que la verdadera libertad consiste en no hacer depender de nadie más que de uno mismo la reglamentación de la propia conducta" (ibíd.).

El examen del concepto de autonomía indica que Bobbio lo usa para referirse no sólo al ámbito de lo "auto-obligatorio", sino también a lo que autores como Habermas denominan autonomía pública (1998, 149-150), es decir, a la competencia del sujeto para participar en la democracia. En este sentido, Bobbio sostiene que en virtud de la autonomía, "todo ser humano debe participar directa o indirectamente en la formación de las normas que deberán regular más tarde su conducta en aquella esfera que no está reservada al dominio exclusivo de su jurisdicción individual" (Bobbio, 1963). Con todo, en este punto su énfasis parece ser inconsistente, pues a veces se enfoca en la autonomía de la comunidad democrática y la facultad que da al Estado para imponer sus normas a los ciudadanos, y a veces pone de relieve la facultad del ciudadano para intervenir en la conformación de la voluntad general.

\section{Relación entre libertad liberal y libertad democrática}

Bobbio no soslaya que uno de los asuntos más debatidos en la filosofía política ha sido el de establecer la relación entre la libertad liberal y la libertad democrática. Sostiene que es imposible confundirlas, pues cada una se refiere a un ámbito propio.

La teoría liberal define la libertad a partir del individuo aislado, mientras que la teoría democrática parte del individuo como partícipe de una colectividad. Cada teoría responde a una pregunta diferente. Para la teoría liberal: ¿qué significa ser libre para el individuo considerado como un todo independiente?; para la teoría democrática: ¿qué significa ser libre para un individuo considerado como parte de un todo? A su vez, cada una de estas preguntas se refiere a un problema de fondo particular. Para la libertad liberal, el problema de los límites 
de la acción del Estado. Para la libertad democrática, el asunto de los límites a la legislación no heterónoma (Bobbio, 1965).

Por esta razón, las dos libertades son inconfundibles e insustituibles. Como Bobbio señala con agudeza, siempre puede existir la una sin la otra: "se puede hablar de una acción limitadora de la libertad, querida libremente", como cuando un fumador decide no fumar tras una madura reflexión, y de "una acción libre, cuya libertad no he querido libremente", como cuando un fumador vuelve a fumar porque ha recibido un permiso de su médico (Bobbio, 1955).

De manera análoga, cada una de estas libertades ofrece ventajas que la otra no puede ofrecer. Por ejemplo, si el Estado es cada vez más invasor y esta invasión resulta inevitable, la libertad democrática intenta "que los límites se conviertan, en la medida de lo posible, en autolimitaciones, en el sentido de que los límites a la libertad vengan señalados por los mismos que deben sufrirlos". Si no es posible evitar que el ciudadano esté menos impedido que antes, "tratemos al menos de que esté menos constreñido" (ibíd.).

Sin embargo, Bobbio es consciente de que las posibilidades de realización de la autonomía son más hipotéticas que reales, porque la democracia real no es directa ni consensual, sino representativa y fundada en el principio mayoritario. Este modus operandi de la democracia implica que las decisiones de los representantes se deben imputar a los representados y que la voluntad de la mayoría también gobierna a las minorías. Por esta razón, es necesario tener presente que así la libertad liberal haya surgido para combatir al Estado absoluto de la minoría, también debe regir para controlar a la mayoría. La suposición de que la extensión del ejercicio del poder de los pocos a los muchos no haría necesario fijar límites liberales, ha demostrado ser quimérica. Como esta extensión del ejercicio del poder a la mayoría es institucionalmente imperfecta, subsisten las razones para trazar límites estrictos e independientes al ejercicio del poder público (ibíd.).

Con todo, y en este aspecto el pensamiento de Bobbio concuerda con el de muchos otros autores - Rawls el más destacado-, existe una razón de más peso para considerar a la libertad liberal como concepto independiente y aun como presupuesto de la libertad democrática: el reconocimiento de que la propia voluntad como autonomía presupone la libertad como no impedimento. Como dice Bobbio: "no puede existir una sociedad en la que los ciudadanos den lugar a una voluntad general en sentido rousseauniano sin ejercitar ciertos derechos fundamentales de libertad" (ibíd.). Si se está de acuerdo en que la autonomía, en sentido político, consiste en que las normas 
lleguen a ser conformes con los deseos de los ciudadanos, en que las normas que se obedezcan sean íntimamente queridas y proclamadas (Bobbio, 1963), se debe aceptar que para ello es indispensable que los ciudadanos puedan pensar y expresarse libremente, sin ningún impedimento.

Lo anterior no excluye que las dos libertades sean complementarias y que se puedan reconducir a un significado común: el de "autodeterminación": "la esfera de lo permitido, en definitiva, es aquella en la que cada cual actúa sin constricción exterior, lo que es tanto como decir que actuar en esta esfera es actuar sin estar determinado más que por uno mismo; $y$, del mismo modo, que un individuo o un grupo no obedezcan otras leyes que las que se han impuesto a sí mismos significa que dicho individuo o dicho grupo se autodetermina". "La libertad como ausencia de impedimentos (obrar como mejor le parezca) coincide con la libertad como autodeterminación (sin depender de la voluntad de ningún otro)" (Bobbio, 1965).

No obstante, aun en el marco de este significado común, existe una diferencia entre la teoría liberal y la teoría democrática de la libertad: "la primera tiende a ensanchar la esfera de la autodeterminación individual, restringiendo todo lo posible la del poder colectivo; la segunda tiende a ensanchar la esfera de autodeterminación colectiva, restringiendo todo lo posible la regulación de tipo heterónomo" (ibíd.). Es en esta diferencia donde se hacen compatibles y complementarias. La fórmula de las libertades señalaría que: "hasta donde sea posible, hay que dar rienda suelta a la autodeterminación individual (libertad como no impedimento); donde ya no sea posible, tiene que intervenir la autodeterminación colectiva (libertad como autonomía)" (ibíd.).

\section{Libertad positiva}

El tercer sentido que Bobbio da al concepto de libertad es el de libertad positiva. Según él, este concepto es resultado de una mutación ocasionada por la influencia de las teorías socialistas del siglo xıx. A causa de esta mutación, no sólo se habla de libertad para aludir al sentido liberal negativo, sino también cuando se sostiene que la garantía de la libertad debe abarcar el poder positivo, es decir, la "capacidad jurídica y material de concretar las posibilidades abstractas garantizadas por las constituciones liberales" (Bobbio, 1963).

Este poder positivo o capacidad jurídica y material se refiere explícitamente al poder efectivo que debe tener todo ser humano para "traducir a comportamientos concretos los componentes abs- 
tractos previstos por las normas constitucionales que atribuyen este o aquel derecho" (ibíd.). De manera más explícita, aquí la libertad impone que todo ser humano posea "en propiedad o como parte de una propiedad colectiva los bienes suficientes para gozar de una vida digna". Esta libertad alude a una capacidad económica suficiente para satisfacer necesidades fundamentales de la vida material y espiritual sin la cuales la libertad liberal sería vacía y la libertad democrática, estéril (ibíd.).

Por último se debe señalar que los derechos sociales representan la concreción más adecuada de esta tercera libertad. Como dice Bobbio:

si sólo existiesen las libertades negativas [...] todos serían igualmente libres pero no todos tendrían igual poder. Para equiparar a los individuos, reconocidos como personas sociales, también en poder, es necesario que se les reconozcan otros derechos como los derechos sociales, derechos capaces de colocarlos en condición de tener el poder de hacer aquello que es libre hacer (Bobbio, 1982).

\section{UNA CRÍTICA DE LOS CONCEPTOS DE LIBERTAD DE BOBBIO}

Es innegable el aporte de Bobbio al esclarecimiento del concepto de libertad mediante las elucubraciones que hemos reconstruido. No obstante, por lo menos tres aspectos pueden dar lugar a consideraciones críticas: la dicotomía entre libertad negativa y positiva, el hecho de que la libertad negativa no se pueda perfilar como una libertad iusfundamentalmente reforzada, y la consideración de los derechos sociales como concreción de la libertad.

\section{LIBERTAD NEGATIVA Y POSITIVA}

Una primera objeción al sistema de libertades que propone Bobbio es que la diferencia entre libertad liberal y autonomía, en tanto reconstrucción, no refleja todos los matices de la diferencia entre libertad negativa y positiva, presente en casi todo el léxico de la libertad desde la Antigüedad.

Quizás Isaiah Berlin sea quien con mayor brillantez y claridad ha expuesto la dicotomía entre libertad negativa y positiva, que incluso en nuestra jurisprudencia constitucional tiene una importancia destacable. No es un detalle sin importancia que el salvamento de voto a la sentencia C-221 de 1994, sobre la despenalización del consumo de droga, esté encabezado por la conocida frase de Mazzini: "la verdadera libertad no consiste en el derecho a escoger el mal, sino en el 
derecho a elegir sólo entre las sendas que conducen al bien”. Es posible considerar esta frase como una definición estándar del concepto de libertad positiva. Según este concepto, reconstruido por Berlin, al sujeto le está atribuida la libertad de acometer sólo aquellas conductas que sean razonables y necesarias (Berlin, 1958, 200-201). Como se sabe, este concepto de libertad es el que aparece en las doctrinas religiosas, morales y éticas que buscan la salvación o la perfección del hombre. Por ejemplo, en el evangelio de Juan, Jesús pregona que la esclavitud proviene del pecado y la libertad surge de conocer y practicar la palabra. La verdad nos hace libres, aquella verdad donde aparece lo único razonable y debido ${ }^{3}$.

En el campo jurídico, este concepto corresponde a la libertad de los regímenes autoritarios y totalitarios. Si rememoramos nuestra historia constitucional, vemos que este interrogante es pertinente. Durante aciagos períodos de nuestra vida política, el concepto de libertad positiva se ha impuesto de facto como concepto constitucional; sobre todo cuando el fundamentalismo católico se ha hecho con el poder político y ha confundido al Estado con la Iglesia y al ciudadano con el feligrés, sin duda para atribuirse el monopolio para determinar el contenido de la libertad observada desde el punto de vista religioso, y fijar el contenido de la libertad política y jurídica.

En filosofía política, el concepto de libertad positiva siempre ha coexistido con el de libertad negativa. De acuerdo con este último, el individuo no sólo es libre de hacer lo razonable o necesario, sino de hacer o dejar de hacer lo que quiera, sin intervenciones externas del Estado o de otros individuos (Berlin, 1958,191). También tiene raíces en la Antigüedad, como ilustra la cita del Deuteronomio, en que Dios declara haber puesto delante del hombre "la vida y el bien, la muerte y el mal”, y, así, de haberle dado libertad para elegir su propio rumbo ${ }^{4}$. Se trata de la libertad de arbitrio que Kant proclamó y entendió como "la independencia de la determinación" de cada cual por sus impulsos sensibles (Kant, 1997, 29 y ss.). Además, aclaró que esta concepción de la libertad jurídica como libertad negativa no elimina la libertad positiva, sino que la reserva para el fuero interno del individuo, para su órbita como creyente, como laico o sujeto ético.

Esta libertad se aparta de toda interpretación perfeccionista ${ }^{5}$. Garantiza un ámbito reservado al individuo, un espacio para tomar sus

${ }^{3}$ Juan 8: 31 y s.

${ }^{4}$ Deuteronomio 30: 15.

${ }^{5}$ Para profundizar sobre la incompatibilidad entre el perfeccionismo y la idea de libertad constitucional, ver Nino (1997, 76 y ss.). 
decisiones vitales; en el sentido de Locke, correlativo a un ámbito en donde el poder está ausente -en el sentido de Hobbes- (Hofmann, 2002, 197 y ss.). Es una libertad negativa porque en su ámbito se niega el poder externo, la heteronomía. Así también lo ha reconocido entre nosotros la Corte Constitucional en una extensa línea jurisprudencial: "No corresponde al Estado ni a la sociedad, sino a las propias personas -sostiene la Corte- decidir la manera como desarrollan sus derechos y construyen sus proyectos y modelos de realización personal"'.

Es evidente que la reconstrucción de la libertad liberal de Bobbio sí logra reflejar por entero y con toda precisión el sentido de la libertad negativa. Pero su concepto de autonomía no da cuenta de aquello que traduce la libertad positiva. Que el individuo se dé normas a sí mismo es diferente de que sólo puede hacer lo bueno y lo razonable. Es cierto que el concepto de libertad negativa no es el adecuado en un Estado constitucional de derecho. No obstante, esto no le resta importancia como concepto de libertad en los ámbitos de la ética y de la moral y no sirve como argumento para negar que para muchos pensadores autoritarios haya sido el concepto político y jurídico adecuado de libertad, deplorablemente. La libertad positiva es un significado descriptivo de la libertad que el concepto de autonomía no logra expresar.

\section{LIBERTAD IUSFUNDAMENTALMENTE REFORZADA}

Una segunda objeción es que el concepto de libertad negativa que defiende Bobbio corresponde a un conjunto de conductas irrelevantes para el derecho y es en cierto sentido incompatible con la idea de libertad iusfundamentalmente reforzada, como aquella que en el artículo 16 de nuestra Constitución garantiza el derecho al libre desarrollo de la personalidad: "todas las personas tienen derecho al libre desarrollo de la personalidad sin más limitaciones que las que imponen los derechos de los demás y el orden jurídico”.

Es cierto que la libertad negativa tiene un contenido universal, que comprende todas las opciones humanas que se puedan emprender, es decir, todas las conductas posibles. Por ende, su número de conductas es infinito y va de asuntos tan triviales como beber un vaso de agua hasta asuntos tan complejos como crear una red de servidores de Internet. Además, el objeto de la libertad evoluciona

\footnotetext{
${ }^{6}$ Ver, entre otras, la T-516 de 1998.
} 
con los tiempos, se recrea, cambia y por ello elude las previsiones de todo poder jurídico, por visionario y garantista que sea. Por esta razón, muchos de los contenidos de la libertad negativa no pueden ser siquiera previstos por el constituyente ni por el legislador, mediante prohibiciones, mandatos o permisos. En este ámbito se enmarcan asuntos tan heterogéneos como la posibilidad de contraer matrimonio, de vivir en unión libre o seguir soltero, de ser madre, elegir el propio nombre, escoger la opción sexual, definir la apariencia o la clase de educación que se quiera o el procedimiento médico que se está dispuesto a aceptar cuando se está enfermo ${ }^{7}$. Todas estas posibilidades que forman parte de la libertad no comprendida en las libertades constitucionales específicas se incluyen entonces en el contenido del derecho al libre desarrollo de la personalidad, que en este sentido se erige como cláusula general residual de libertad. La libertad negativa abarca todo el espectro de conductas humanas posibles, en el pasado, en el presente y en el futuro. En el Estado de derecho, la libertad negativa cumple la función de cláusula de cierre del ordenamiento jurídico. Por efecto de esta cláusula, todo lo que no está prohibido por la Constitución o por las normas jurídicas de jerarquía inferior está permitido, es decir, representa una posición jurídica de libertad.

Cabe preguntar, sin embargo: ¿qué estatus jurídico tiene esta cláusula general residual de libertad - es decir, la libertad negativa- en el Estado constitucional?

En el modelo del Estado liberal, el contenido de esta cláusula era el ámbito del agere licere, aquello a lo que se refiere Bobbio, es decir, el espacio compuesto por todas las acciones irrelevantes para el derecho, o, en otros términos, las que aún no han sido objeto de regulación jurídica. El conocido mito liberal de la fundación de la sociedad civil a partir del estado de naturaleza ofrecía un sustento idóneo para considerar acciones libres a las acciones irrelevantes o no reguladas. La libertad natural, inherente al hombre, debía ser, aun en la sociedad civil, la regla general y, por ello, junto a las acciones prohibidas, ordenadas o permitidas por el derecho, las acciones naturales no reguladas aparecían como acciones libres.

Pero se trataba de una libertad natural, no protegida jurídicamente. El ámbito de agere licere estaba expuesto a inminentes intervenciones

${ }^{7}$ Para un detallado análisis de las principales sentencias concernientes al derecho al libre desarrollo de la personalidad, ver N. Osuna, A. Julio et al., "E1 derecho al libre desarrollo de la personalidad en la jurisprudencia constitucional", manuscrito. 
del poder público. Ni el legislador ni la administración tenían límites para restringirlo. El resultado incuestionable de toda restricción era el cambio automático en el estatus de la conducta. Por ejemplo, si una ley prohibía u ordenaba una conducta hasta entonces irrelevante, esta regulación era incuestionable. No valía ningún argumento contra ella. Los demás poderes públicos y los particulares estaban sujetos a sus prescripciones. La libertad había desaparecido, se había negado, había devenido en no libertad.

La única forma en que el agere licere podía resistir las intervenciones del poder público era que se transformara en un permiso legislativo. Cuando el legislador permitía una conducta naturalmente libre, la libertad se reforzaba, se convertía en una libertad jurídicamente protegida. En este caso, ni la administración ni los particulares podían prohibir u ordenar lo que ya permitía el legislador, no podían obstaculizar el ejercicio de la libertad reforzada por el derecho. Sin embargo, el contenido del agere licere nunca podía ofrecer resistencia a los designios legislativos. Razón tenía Montesquieu (1748) al definir la libertad mediante su conocida fórmula: "la libertad es el derecho de hacer todo lo que las leyes permiten".

Este panorama se modifica sustancialmente en el Estado constitucional con la introducción del derecho al libre desarrollo de la personalidad, que implica la constitucionalización del ámbito de agere licere y tiene consecuencias de hondo calado. En primer lugar, se constitucionaliza todo el ámbito de la libertad negativa no contenido en las libertades específicas. Como consecuencia, y en segundo lugar, la regulación de este ámbito deja de estar a merced del poder público y, en especial, a merced del legislador. Ya no se trata de la libertad en la medida de la ley, sino de la ley en la medida de la libertad. La ley deja de definir el ámbito de la libertad resistente a las intervenciones del poder público. Muy al contrario, el respeto de la libertad constitucionalizada comienza a ser la medida de la validez de la ley, de los actos administrativos y judiciales, y de la conducta de los particulares. Sólo merecen tener validez en sentido material las normas jurídicas que respeten la libertad constitucional.

De este modo, el ámbito de agere licere desaparece como tal y el contenido de la cláusula general de libertad se transforma en el contenido del derecho al libre desarrollo de la personalidad. Este derecho se empieza a concebir como un derecho fundamental general de libertad. Y del horizonte del derecho desaparece el espectro de las conductas jurídicamente irrelevantes. Toda libertad aún no regulada por el Estado forma parte, prima facie, del contenido del derecho al 
libre desarrollo de la personalidad. Las libertades aún no reguladas se suman a las libertades expresamente protegidas por la Constitución y conforman el conjunto de lo constitucionalmente permitido prima facie. Mientras que en el Estado liberal todo lo que no está prohibido está permitido como parte de la libertad natural, sin ninguna protección jurídica, en el Estado constitucional todo lo que no está prohibido u ordenado por la Constitución está permitido prima facie por las libertades constitucionales específicas o, de manera residual, por el derecho al libre desarrollo de la personalidad. Toda libertad natural es ahora relevante para la Constitución, es una libertad constitucionalmente protegida.

Por todo lo anterior, el concepto de libertad negativo de Bobbio es refutable desde el punto de vista de la filosofía jurídica, por cuanto refleja tan sólo la existencia de un agere licere pero no da cuenta de la existencia de un derecho general fundamental de libertad.

\section{¿SON LOS DERECHOS SOCIALES DERECHOS DE LIBERTAD?}

Por último, parece refutable el tercer concepto de libertad de Bobbio, como poder de disposición de los medios materiales para ejercer la libertad. Este aspecto parece formular la tesis de que los derechos sociales se deben entender como derechos de libertad o, dicho en sentido contrario, que uno de los significados de la libertad se concreta en los derechos sociales.

Es más coherente plantear que la garantía de los derechos sociales es una garantía de la libertad o que los derechos sociales tienen una fundamentación independiente. En todo caso, lo que no parece consistente es atribuir a estos derechos el estatus de significados de la propia libertad. A este respecto se debe decir que en el Estado social de derecho los derechos sociales se pueden fundamentar de dos formas: de manera independiente o como medios para garantizar el ejercicio real de las libertades.

E. Tugendhat ofrece una notable fundamentación filosófico política independiente de los derechos sociales en el marco del Estado social de derecho. Su idea central es que para responder la pregunta acerca de qué derechos debe tener una persona "sólo puede ser fundamental el concepto de necesidad" (1997, 344-345). De acuerdo con Tugendhat, los derechos fundamentales establecen reglas de cooperación social que trazan las condiciones en las que se desarrollan los vínculos entre los individuos, y entre estos y el Estado. El contenido de estas reglas de cooperación no es inmutable, sino 
que se asigna en cada época, de acuerdo con los valores e intereses predominantes o de conformidad con las reivindicaciones que se imponen como resultado de las luchas sociales. Así, la convicción liberal de que los derechos fundamentales se traducen únicamente en deberes estatales de abstención no es más que un reflejo del pensamiento burgués que echa sus raíces en el contractualismo ilustrado (ibíd., 321-322). El pensamiento burgués presupone que la sociedad está integrada por individuos dotados de un alto grado de poder; de adultos aptos para el trabajo, capaces de satisfacer por sí mismos sus necesidades y emprender proyectos útiles para sus intereses. La única necesidad que tiene este conjunto de individuos -exitosos y autónomos en sentido kantiano- es la de protegerse de los ataques externos. El credo de la autosuficiencia del hombre permite fundamentar un sistema de derechos compuesto exclusivamente por obligaciones de abstención, que busca proteger al sujeto de toda intervención externa.

Tugendhat se esfuerza por mostrar que esta idealización de la sociedad propia del liberalismo no corresponde con la circunstancia real de que "grandes sectores de la comunidad no pueden valerse por sí mismos" (ibíd., 338-339). El sistema de derechos fundamentales no se puede sostener sobre la presunción errada de que la sociedad está integrada totalmente por individuos capaces, autónomos y autosuficientes, que además intervienen en condiciones de igualdad en la toma de decisiones políticas. Es imperioso reconocer que el liberalismo presupone más individuos capaces de ser ciudadanos libres que los que existen en la práctica.

Ante este desfase de la concepción burguesa, Tugendhat sugiere construir un sistema de derechos fundamentales arraigado en el concepto de necesidad. La idea de necesidades inherentes al hombre no es del todo incompatible con el liberalismo. Por esta razón, se puede enmarcar en el Estado social de derecho. En las nociones de libertad negativa y de autonomía, que fundamentan la concreción de los derechos fundamentales en deberes de abstención, subyace también el reconocimiento de que el individuo tiene necesidad de elegir y de decidir su propio rumbo. Ejercer la libertad es también una necesidad humana. No obstante, la idea de necesidad se extiende a otros planos, soslayados por el pensamiento burgués. Esta idea pone de relieve que la situación de carencia de los bienes indispensables para subsistir y ejercer las libertades, en que se encuentran vastos sectores de la población de los Estados, es un hecho de gran relevancia social. Ninguna sociedad que pretenda buscar la justicia puede dejar la satisfacción 
de las necesidades básicas, que comienzan por la alimentación ${ }^{8}$, al arbitrio del azar económico.

De lo anterior se sigue que el imperativo de satisfacer las necesidades básicas de toda la población da origen a ciertas reglas de cooperación que también integran el contenido de los derechos fundamentales. Estas reglas de cooperación desarrollan el principio de solidaridad ${ }^{9}$, conforman los derechos sociales fundamentales y prescriben deberes de actuar que tienen un doble efecto de irradiación (ibíd., 341-342). En primer lugar se proyectan sobre el propio afectado - a quien su estatus inicial como persona autónoma impone la obligación de autoayuda- y sobre sus familiares y allegados, que tienen con el afectado un vínculo de solidaridad muy estrecho. Pero si estos deberes positivos no se pueden cumplir en esta primera instancia, se traspasan, de modo subsidiario, a todos y cada uno de los miembros de la sociedad, que se aúnan en el Estado para procurar el correspondiente deber prestacional que satisfará el derecho social ${ }^{10}$.

Esta doble irradiación de los deberes que emanan de los derechos sociales tiene la ventaja de que concilia el imperativo de satisfacer las necesidades básicas de cada individuo con su consideración como sujeto autónomo y capaz. Así, los derechos sociales se tornan compatibles con las libertades en el marco del Estado. La doble irradiación indica además cuál es el enfoque preferente que deben adoptar las prestaciones estatales que procuran satisfacer los derechos sociales. En forma prioritaria, estas prestaciones deben brindar a la persona las condiciones necesarias para que se ayude a sí misma, para que

\footnotetext{
8 Para una fundamentación independiente del derecho a recibir alimentación básica, ver Sen (2002).

${ }^{9}$ Borgetto $(1993,398)$ señala que el principio de solidaridad cumple la función de fundamentar en alguna medida ciertos derechos sociales. En esta dimensión, la solidaridad se entiende como un "deber colectivo de ayuda mutua", como un "verdadero principio de acción política". En el mismo sentido, Peces-Barba (1995, 208-209 y 213) afirma que la solidaridad es un "valor que está a la raíz de algunos de los derechos económicos, sociales y culturales y también de nuevos derechos, como los referidos al medio ambiente". También Weber (1995, 678). Sin embargo, el principio de solidaridad no se puede considerar como un fundamento autónomo de los derechos sociales. Este principio fundamenta los deberes de ayuda mutua. Pero, para poder fundamentar los derechos sociales, este principio se debe sumar al concepto de necesidades básicas que enfatiza las posiciones subjetivas del individuo.

${ }^{10}$ Del mismo modo, Gomes Canotilho $(1998,39-40)$ ha hecho ver que el imperativo que se desprende de los derechos sociales vincula a todos los miembros de la sociedad, y se hace efectivo sobre todo por los contribuyentes, quienes proporcionan al Estado los recursos necesarios para atender las prestaciones correspondientes.
} 
pueda velar por su propia subsistencia. Por esta razón deben ser, en lo posible, y estar encauzadas a conseguir que los beneficiarios desarrollen su propia autonomía (Gomes Canotilho, 1998, 49). Así mismo, la concepción de las necesidades básicas lleva a que tanto en las libertades como en los derechos sociales los derechos tengan prioridad sobre los deberes. Así como la necesidad del individuo de ejercer su libertad fundamenta el deber correlativo de abstención del Estado y de los particulares, la necesidad individual de disponer de la procura existencial y de los bienes mínimos para ejercer la libertad fundamenta el deber correlativo de prestación, también a cargo de los demás individuos y, en última instancia, del Estado.

Mediante el concepto de persona como sujeto titular de un conjunto de necesidades, Tugendhat ofrece una fundamentación independiente de los derechos sociales; independiente, porque considera los derechos sociales como fines en sí mismos, y no como meros presupuestos o medios indispensables para ejercer las libertades o los derechos políticos. Este tipo de fundamentación instrumental de los derechos sociales ha prevalecido en la filosofía política y en la dogmática constitucional. Alexy, por ejemplo, sostiene que "el argumento principal a favor de los derechos fundamentales sociales es un argumento de libertad”. Según él, el argumento de libertad indica, en primer lugar, que "la libertad jurídica para hacer u omitir algo sin libertad fáctica (real), es decir, sin la posibilidad fáctica de elegir entre lo permitido, carece de todo valor" (Alexy, 1997, 486); y, en segundo lugar, que "bajo las condiciones de la moderna sociedad industrial, la libertad fáctica de un gran número de titulares de derechos fundamentales no encuentra su sustrato material en un ámbito vital dominado por ellos, sino que depende esencialmente de actividades estatales" (ibíd., 487). En otros términos, Alexy resalta que la satisfacción de las necesidades aparejadas a los derechos sociales por parte del Estado es un medio indispensable para ejercer la libertad jurídica. En razón de este nexo instrumental, se debe considerar que la libertad jurídica se amplía e incluye a los derechos sociales en su ámbito garantizado, es decir, que los derechos sociales se deben considerar como derechos fundamentales en virtud de su función a favor de la libertad. Del mismo modo, Böckenförde $(1993,74)$ señala que los derechos fundamentales sociales encuentran su justificación "ciertamente no como contra-principio frente a los derechos fundamentales de libertad, sino a partir del propio principio del aseguramiento de la libertad": "para que la libertad jurídica se pueda convertir en libertad real, sus titulares precisan de una participación básica en los bienes 
sociales materiales; y esta participación en los bienes materiales es una parte de la libertad, dado que es un presupuesto necesario para su realización" (ibíd.).

Otros autores han reivindicado la fundamentación de los derechos sociales no sólo como medios para ejercer las libertades, sino también los derechos políticos. A título de ejemplo, vale traer a colación el papel de los derechos sociales en la concepción de Habermas, como medios para disfrutar en condiciones de igualdad los derechos individuales y políticos (Habermas, 1998,189). Y como argumento a favor de la atribución de la mayor fuerza jurídica posible a los derechos sociales, Gomes Canotilho $(1997,432)$ aduce que "por debajo de un cierto nivel de bienestar material, social, de aprendizaje y de educación (que ellos garantizan), las personas no pueden tomar parte en la sociedad como ciudadanos, y mucho menos como ciudadanos iguales" (cursivas mías).

En contra de estas concepciones instrumentales, Tugendhat sugiere que los derechos sociales se deben considerar como fines en sí mismos. A su juicio, la idea de que la libertad constituye el único fin digno de protección en el Estado constitucional es una derivación del mito burgués del Estado de naturaleza, que considera al hombre como un ser dotado de libertad absoluta. La gran deficiencia de este mito es que idealiza a un hombre que no existe, a un "Robinson Crusoe" capaz de subsistir aislado el mundo, sin contacto con los demás, y olvida que "ningún individuo habría podido sobrevivir jamás si no hubiera nacido dentro de una comunidad" (Tugendhat, 1997, 344). En el mundo real, todos los individuos pasamos por lo menos por una etapa (la niñez), en la que no podemos velar por nosotros mismos. Esta circunstancia se repite en la vejez, y para muchos es una constante durante toda su existencia. Los deberes de solidaridad correlativos a los derechos sociales, que favorecen a quienes no pueden velar por sí mismos, no tienen como fin prioritario patrocinar el ejercicio de la libertad sino proveer lo necesario para su subsistencia en condiciones dignas. Según Tugendhat, lo que importa en realidad es reconocer que el hombre tiene determinadas necesidades que le son inherentes, y cuya satisfacción es uno de los fines principales de la comunidad política. Esas necesidades fundamentan los derechos sociales (que buscan satisfacer las necesidades materiales, vitales y físicas), los derechos de libertad (que intentan colmar las necesidades que subyacen en el ejercicio de la libertad), y los derechos políticos (relativos a las necesidades de cooperación política con los demás). Así, las normas que tipifican los derechos sociales no son sólo un 
medio para la realización de la libertad, tienen la finalidad propia de ofrecer a todos los individuos las condiciones mínimas para satisfacer sus necesidades básicas y llevar una existencia digna. En este sentido, los derechos fundamentales sociales tienen el carácter de derechos atribuidos, sobre todo para quienes sufren carencias ${ }^{11}$.

A nuestro modo de ver, la fundamentación independiente que propone Tugendhat no es contradictoria, sino complementaria, con la fundamentación instrumental de los derechos sociales. Este nexo de complementariedad se produce en razón de que el ámbito de los derechos sociales tiene un contenido muy amplio, que no sólo abarca las disposiciones que buscan garantizar un mínimo existencial para el individuo sino también las normas que conforman la dimensión prestacional de las libertades y de los derechos políticos.

Cuando comparamos estos planteamientos con la idea de libertad positiva de Bobbio, tenemos que resaltar su intuición de fundamentar los derechos sociales como presupuesto para la realización de la libertad liberal o libertad en sentido negativo. Con todo, la distinción entre categorías es clara y por ello es impropio referirse al derecho a disponer de los medios necesarios para ejercer la libertad con el concepto de libertad.

\section{REFERENCIAS BIBLIOGRÁFICAS}

Alexy, R. 1997. Teoría de los derechos fundamentales, Madrid, Centro de Estudios Políticos y Constitucionales.

Baldassarre, A. 1998. "Los derechos sociales", Revista de Derecho del Estado 5. Reproducido como Los derechos sociales, Bogotá, Universidad Externado de Colombia, 2001.

Berlin, I. 1958. Two Concepts of Liberty, Oxford, Clarendon Press. Publicado en español como "Dos conceptos de libertad", Cuatro ensayos sobre la libertad, Madrid, Editorial Alianza.

Bobbio, N. 1955. "Della libertà dei moderni comparata a quella dei posteri", Politica e cultura, Einaudi, Torino, pp. 160 y ss. Publicado en español como "De la libertad de los modernos comparada con la de los posteriores", Teoría general de la politica, Madrid, Editorial Trotta, 2003, pp. 293-322.

Bobbio, N. 1963. "Eguaglianza e dignità degli uomini", AA. vv., Diritti dell'uomo e Nazioni unite, Padova, Cedam. Reimpreso en Il terzo assente, Torino, Sonda, 1989, pp. 71-83. Publicado en español como "La Declaración Universal de los Derechos del Hombre", Teoría general de la política, Madrid, Editorial Trotta, 2003, pp. 520-533.

Bobbio, N. 1965. "Kant e le due libertà”, Da Hobbes a Marx, Napoli, Morano, pp. 147 y ss. Publicado en español como "Kant y las dos libertades", Teoría

${ }^{11}$ Ver Peces-Barba (1998, 28), Prieto (1995) y Baldassarre $(1998,13)$. 
general de la politica, Madrid, Editorial Trotta, 2003, pp. 113-127.

Bobbio, N. 1976. "Eguaglianza ed egualitarismo", Rivista internazionale di Filosofia del Diritto 53, 3. Reimpreso en AA. vv., Eguaglianza ed egualitarismo, Roma, Armando, 1978, pp. 13-25. Publicado en español como "Igualdad e igualitarismo", Teoría general de la politica, Madrid, Editorial Trotta, 2003, pp. 323-332.

Bobbio, N. 1982. "I diritti dell'uomo e la pace", AA. vv., La pace, Milano, Edizioni Cens. Reimpreso en Il terzo assente, Torino, Sonda, 1989, pp. 92-96. Publicado en español como "Los derechos, la paz y la justicia social”, Teoría general de la política, Madrid, Editorial Trotta, 2003, pp. 533-546.

Bobbio, N. 1988. Teoría general del derecho, Bogotá, Temis.

Bobbio, N. 1996. "Sui diritti sociali”, G. Neppi Modona, ed., Cinquant'anni di Repubblica italiana, Torino, Einaudi, pp. 115-124.

Böckenförde, E. W. 1993. "Los derechos fundamentales sociales en la estructura de la Constitución", Escritos sobre derechos fundamentales, Nomos, Baden-Baden.

Borgetto, M. 1993. La notion de fraternité en droit public français, Paris, LGDJ.

Bovero, M. 2003. "Introducción. La idea de una teoría general de la política”, N. Bobbio, Teoría general de la politica, Madrid, Editorial Trotta.

Constant, B. 1980. "De la liberté des anciens comparée a celle des modernes", De la liberté chez les modernes. Ecrits politiques, Paris.

Gomes Canotilho, J. J. 1997. Direito constitucional e teoria da constituição, Almedina, Coimbra.

Gomes Canotilho, J. J. 1998. “Metodología 'fuzzy' y 'camaleones normativos' en la problemática actual de los derechos económicos, sociales y culturales", Derechos y Libertades 6, pp. 39 y s.

Habermas, J. 1998. Facticidad y validez. Sobre el derecho y el Estado democrático de derecho en términos de teoría del discurso, Madrid, Trotta.

Hofmann, H. 2002. Filosofía del derecho y del Estado, Bogotá, Universidad Externado de Colombia.

Kant, I. 1997. Introducción a la teoría del derecho, Madrid, Marcial Pons.

Montesquieu, C. 1748. De l'esprit des lois, Paris, Garnier. Publicado en español como El espíritu de las leyes, Madrid, Tecnos, 1995.

Nino, C. S. 1997. La Constitución de la democracia deliberativa, Barcelona, Gedisa.

Passerin D'Entreves, A., ed. 1974. La libertà politica, Milano, Edizioni di Comunità.

Peces-Barba, G. 1995. Curso de derechos fundamentales, teoría general, Madrid, Universidad Carlos in de Madrid.

Peces-Barba, G. 1998. "Los derechos económicos, sociales y culturales: su génesis y su concepto", Derechos y Libertades 6, 1998.

Prieto S., L. 1995. "Los derechos sociales y el principio de igualdad sustancial", Revista del Centro de Estudios Constitucionales 22, 1995.

Sen, A. K. 2002. El derecho a no tener hambre, Bogotá, Universidad Externado de Colombia.

Tugendhat, E. 1997. Lecciones de ética, Barcelona, Gedisa.

Weber, A. 1995. "L'État social et les droits sociaux en RFA", Revue Française de Droit Constitutionnelle 24.

Revista de Economía Institucional, vol. 8, N. ${ }^{\circ}$ I4, Primer semestre/2006 